\title{
Research on Planning of Network Platform PC and APP Ends of Ou Palace Wine
}

\author{
LeDan Huang \\ Wenzhou Vocational \& Technical College, Wenzhou. 325035 \\ LeDan@sina.com
}

Keywords: Website building; APP; Building; Platform.

\begin{abstract}
With the rapid development of Internet, people becoming busier day by day are beginning to use domestic Internet, a powerful platform, to do business online. It is not the strongest of the species that survive, but the one most responsive to change. Since our team's project is to build Ou Palace's network brand, it's very important to build an owner website and APP. Combined with Ou Palace wine's characteristics and culture, analysis of building a website and APP with owner style will be made in the article. Particulars of the most important part of the website shall be given.
\end{abstract}

\section{Introduction}

The global development of Internet has profound influence on people's life and modes of production. According to reckoning, by the end of 2017, Chinese Internet users will be up to about 1 billion, wherein mobile Internet users have been the majority. Building enterprise portal website and setting up enterprise network image has become the best method for an enterprise to adapt for the development of information age. A portal website with beautiful design and perfect function has been an important content of the enterprise network building, and Ou Palace's network platform PC and APP ends are constructed based on a team project according to the condition of Ou Palace. In addition, corresponding solutions to problems possibly caused in the building should be proposed.

\section{Website Building}

\subsection{Planning of Website Contents}

Different types of websites are greatly different in structure. A website is based on a column structure. A website structure suitable for Ou Palace is designed according to Ou Palace's current condition and demand. The column structural diagram is below Figure 1.

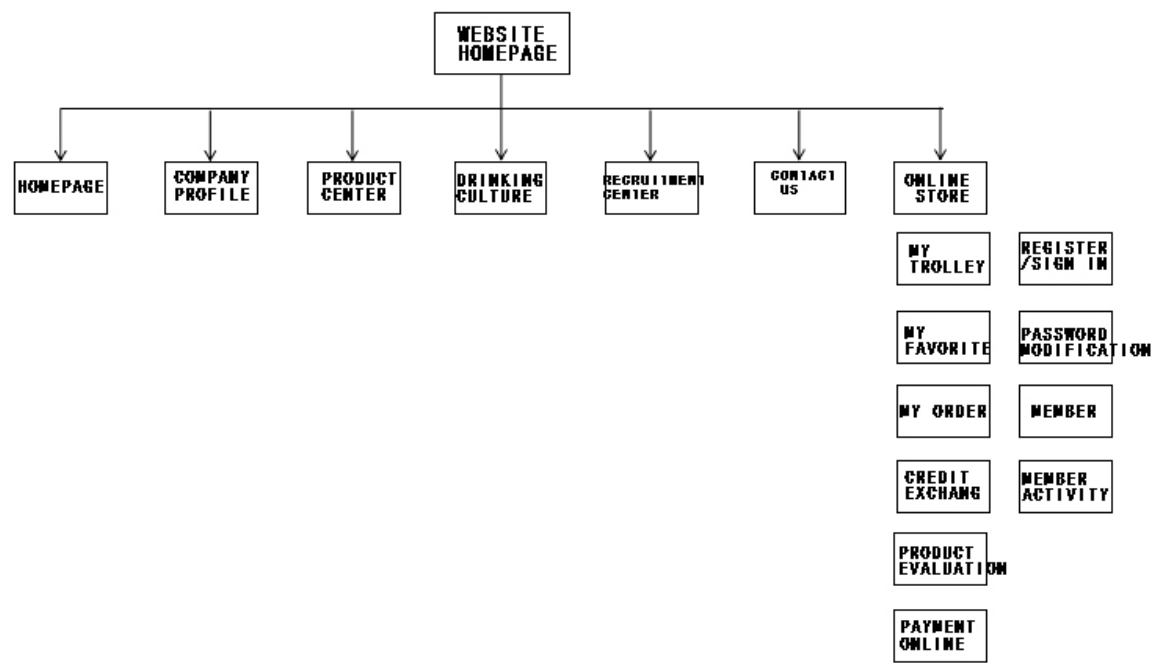

Figure 1 Column Structural Diagram 


\subsection{Description of Columns}

\subsubsection{Homepage}

A homepage is the appearance and soul of a website, and a key of attracting visitors to pay a further visit to the website. Therefore, the homepage must be beautiful, magnificent, harmonious in color matching and abundant in content but not out of order, should play a good role of guidance, and enables the visitors to know where information to be browsed is. Columns including company profile, product center, drinking culture, recruitment center, contact us and online store are going to be arranged on the homepage.

\subsubsection{Company profile}

The column is for the purposes of brief introduction to the company, customers' further understanding, improvement of competitive power, and promotion of development.

\subsubsection{Recruitment center}

The column is for the purpose of making visitors interesting in the company to submit their resumes here and joining it after interviews.

\subsubsection{Contact us}

The column is for the purposes of public relation and convenience to contact.

\subsubsection{Online store}

The column is for the purpose of displaying all products and has function of collection, adding into shopping cart, online payment, etc. Cheaper products can be purchased here.

\section{Special column}

A special column shall be arranged on the website. Registered users of the website can inquiry that whether today's drinking is excessive according to a sensor's prompt, whether the drinking facilitates the users' physical condition, accordingly, better experience is brought to the users, and further more user are attracted. This is the special column.

\section{Homepage photo}

Core Technology and Running Environment

Database Structural Diagram

A good database can be improved in data query efficiency. Rationalizing form structure, arranging physical storage partition and adding index and the like can improve the speed of data reading and further boost inquiry efficiency. The database structural diagram is below Figure 2 .

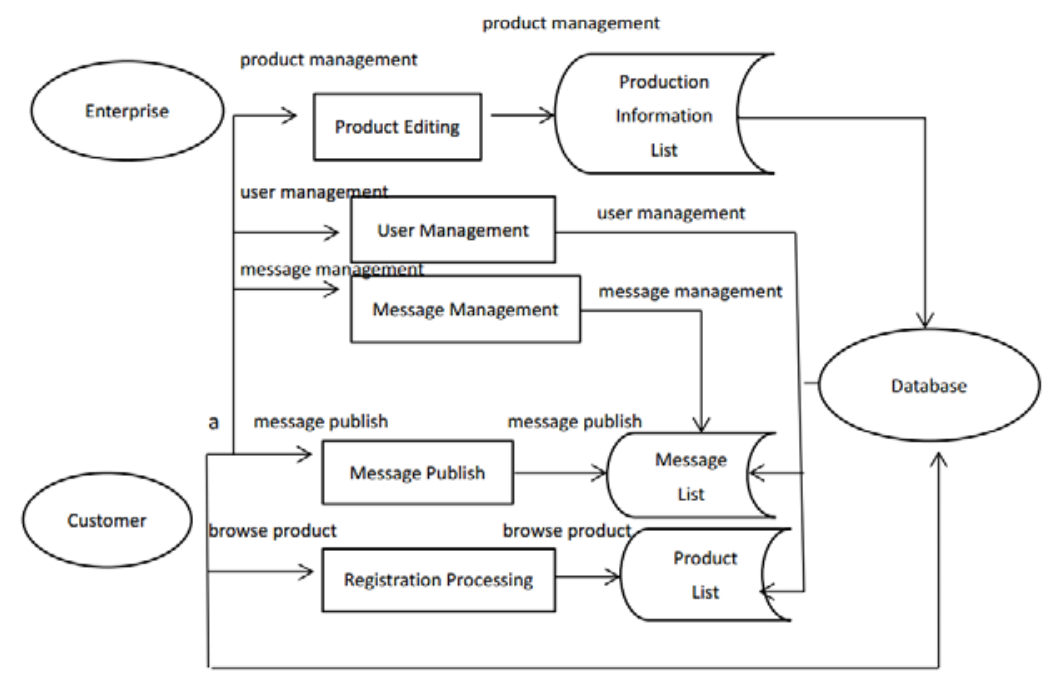

Figure 2 Database Structural Diagram 


\subsection{Description of Webpage Design}

\section{Design concept}

Website design is art expression. Therefore, in various kinds of simple website design, we should always have this sense. Intensity comparison of space and function of the website should make the visitors more comfortable. Selected colors should be reflected between implicity and outstanding. And style and characters should be appropriate in sizes and interlaced in vertical and horizontal directions.

We propose simple design styles. Greatly different customers and demand thereof determine considerable art design style. Minimalism design style has stronger bionergy, and meanwhile is correspond with modern people's still and clear mentality.

\subsection{Design conception}

Firstly, as for the whole webpage layout, since it is a wine website, a simple style should be adopted to the layout. A few characters on the webpages, mainly prompted wines and photos thereof are at the utmost bottom. Secondly, the whole webpage can embody the company's style and conception and personal idea. A thick Chinese wash drawing is as the main body of the homepage. A landscape painting can embody our company's culture, the bottom product displaying zone is red, which is our company's representative color not too brightly colored and dull.

\subsection{Design color}

Color design can bring visual differences and art enjoyment to people. When entering certain of space, people get the first impression is color in $75 \%$ within the first few seconds. Therefore, colors, not be ignored, are important factors of the website.

\subsection{Design process}

Content organization: At the stage of content organization, it requires the designers to express information collected with clear and defined characters, and must ensure that visitors can quickly and accurately understand the website's intention.

Test publish: The test is divided into two parts including a test to integrality and another test to serviceability. The test to integrality ensures the correction of technology. For example, whether the display of webpage is correct or not, the linkage address correct or not. The test to serviceability ensures that the contents of the webpage is required by the visitors, and is suitable for the initial design target. After satisfied tests, the webpage can be published.

\section{Later Maintenance}

A website is a system. Although an enterprise's website system is small, but it's complete. If problems are caused with that the visitors cannot normally browse the webpage and give up an idea of consultation, it's a very serious loss. Therefore, website maintenance is very important. Good later maintenance of the website can avoid the loss of all efforts.

Website Maintenance I: Website safety

Website Maintenance II: Content maintenance and update

Regular update of information ensures that the website is always in an active operation status.

Website Maintenance III: Assurance of normal website visit

Website Maintenance IV: Backup and maintenance of database

Website Maintenance V: Compatibility of browser

\section{Create APP}

\subsection{Arrangement of APP Columns}

Modules include homepage, superior commendation, Chinese drinking culture, foreign drinking culture, Ou Place wines, company activities, company profile, interaction between enterprise and 
customers, as well as enterprise culture transmission. Specially, the module drinking culture is arranged, for the purpose of attracting people like Chinese drinking culture. Much Ou Palace wine culture can be added. Diagram of APP Columns is below Figure 3.

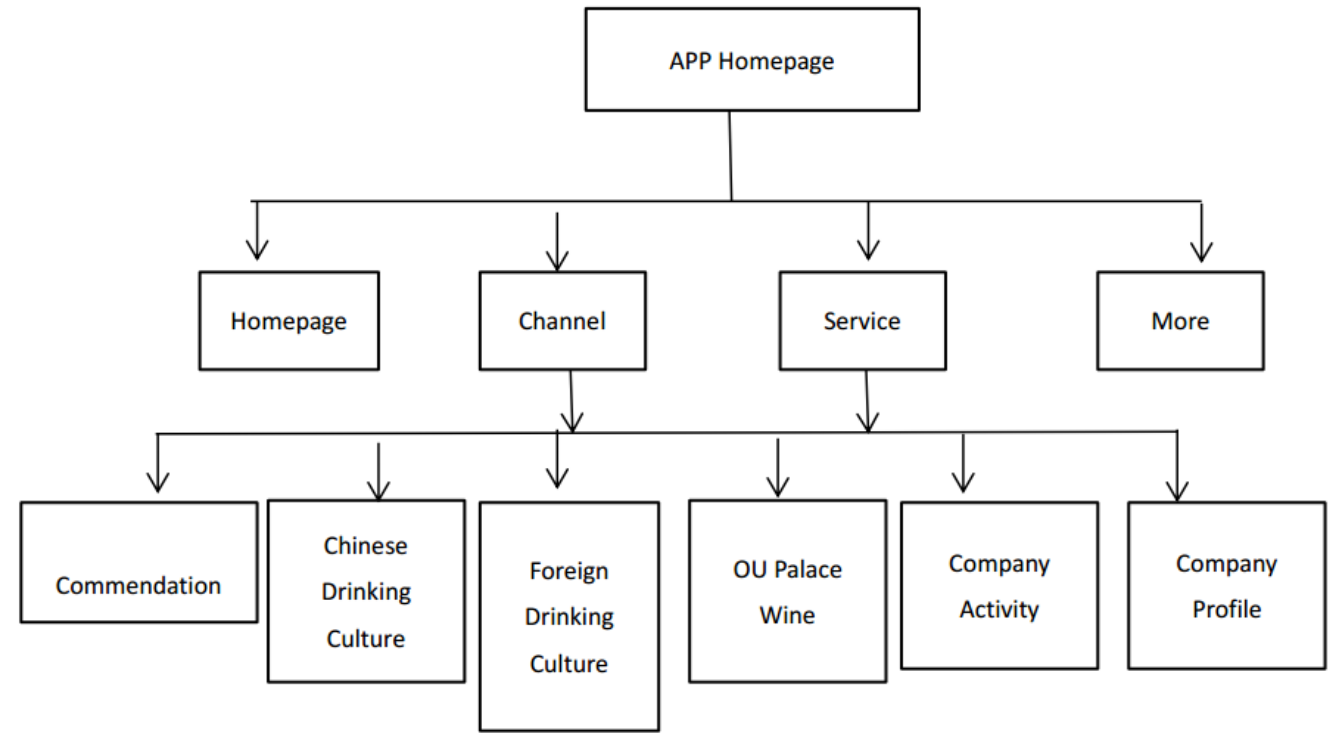

Figure 3 Diagram of APP Columns

\subsection{Design Conception}

A good APP design has a great help for APP building. The design conception shall be stated from the following aspects.

\subsubsection{Visitors}

It's obvious that generally middle-aged men and young men like drinking or Chinese drinking culture. Therefore, the webpage should be classic and commercial, and makes Chinese culture outstanding.

\subsubsection{Operating system}

At present, Chinese mobile phones adopt Android system, of course, some of them use IOS. Therefore, both the two should be developed. If Android is developed only, it's obviously unfriendly to IOS users. Accordingly, it has great effect on the development trend of the company.

\subsubsection{Vision}

It should be classic mainly, simple and generous.

\subsubsection{Others}

The company's contact, customer service, activities, etc.

\subsection{Later maintenance}

Maintenance of developer accounts in application markets, such as Apple store, Android's Pea Pod, Android Market, Carpenter Ant, and 360 Market.

New versions are updated and perfected according to users' feedback and product data analysis after the first version of app is in online.

Promotion of app in various channels, such as Shua Bang Huan Liang, pr advertorial, blogs, WeChat, business cooperation, ditui, hard advertisement and guidance for interaction among users, should be a part of the later maintenance. Because app is hard to exist without promotion. Later maintenance will be free for less loading and installation. 


\section{Difficulties and Measures}

\subsection{Difficulties}

\subsubsection{Building expense over budget}

The budget is a great problem. Since domestic website building companies are scattered and cannot achieve small profit and large scale volume, building a website is just a non-practicable idea of medium-sized and small enterprises with insufficient capital.

\subsubsection{Difficulty in later website maintenance}

Many medium-sized and small enterprises built enterprise official websites at great expenses. However, building a website is not the finish of everything. Later website maintenance is a subsequent task. If lacking of specialists' operation and maintenance and professional action, the operation cost will be increased with the decrease of the visit amount, finally, the website become the enterprise's chicken ribs.

\subsection{Measures}

\subsubsection{Employee professional team}

Website building is wide in range and contents. During building, it's avoidable to have difficulties, but we can make a design, and then transfer the building to a professional team. In this way, the budget can be under the control.

\subsubsection{Create WeChat public number}

A WeChat public number is an application account applied by the developer or business on WeChat public platform. There are 0.5 billion active WeChat users, in this way, the problem of early APP promotion can be solved, and the considerable users can be used to achieve continuous operation.

\subsection{Peroration}

Building a website and APP is a great challenge to the medium-sized and small enterprises. They should find their places, build unique websites and seize their core users. Each step of building is a key hardly. A high-quality website is built through mastering each procedure. It's worth mentioning that complex website structure and sumptuous design cannot achieve high quality. High quality means that the website can bring friendly experience to the users and make them to like the search engine. Although, it's impossible to help the enterprise to build a website right now, the quality of the whole website can be improved.

\section{References}

[1] J. Changhong. Practical Application of Text Font in Page Layout. Northwest Fine Arts. vol. 4, pp. 14-15, 2015..

[2] LIdao-guo. Sign interpreted visual field fuse. Beijing: decoration2008. (11) .

[3] LIUshu-yu. Educating electrical informational production's beauty. Beijing: China publish, (2008).

[4] LIdao-guo. Sign interpreted visual field fuse. Beijing: decoration2008. (11) .

[5] Z. Haidong and X. Lixin, Tips for Using Digital Cameras Well - Common Problems and Solutions for Digital Photography. Digital Printing, vol.7. pp .10-11. 2013. 